\title{
Potencial antagonista e controle in vitro de Alternaria solani por fungos sapróbios
}

\author{
Antônio Jussiê da Silva Solino ${ }^{1}$, Juliana Batista Santos Oliveira ${ }^{1}$, Kátia Regina Freitas Schwan-Estrada ${ }^{1}$, Marianna \\ Santos Rodrigues Alencar ${ }^{1}$ e Lilianne Martins Ribeiro ${ }^{1}$
}

\begin{abstract}
${ }^{1}$ Departamento de Agronomia da Universidade Estadual de Maringá, CP. 5790, 87020-900, Maringá, PR.
Autor para correspondência: Antônio Jussiê da Silva Solino (jussiesolino@hotmail.com)

Data de chegada: 24/03/2016. Aceito para publicação em: 10/05/2017.
\end{abstract}

$10.1590 / 0100-5405 / 2202$

\section{RESUMO}

Solino, A.J.S.; Oliveira, J.B.S.; Schwan-Estrada, K.R.F.; Marianna Santos Rodrigues Alencar, Ribeiro, L.M. Potencial antagonista e controle in vitro de Alternaria solani por fungos sapróbios. Summa Phytopathologica, v.43, n.3, p.199-204, 2017.

Alternaria solani, agente etiológico da pinta preta, é considerado um fitopatógeno de grande impacto econômico na cultura do tomate, gerando grandes prejuízos aos agricultores. O objetivo deste trabalho foi verificar o potencial antagonista por confronto direto, produção de voláteis e atividade antimicrobiana in vitro de filtrado de fungos sapróbios contra $A$. solani. Assim, confrontou-se o fitopatógeno A. solani com os fungos sapróbios Volutella minima, Memnoniella echinata, M. levispora, Curvularia eragrostidis, $C$. inaequalis, Gonytrichum chlamydosporium, G. macrocladum, Pseudobotrytis terrestris, Pithomyces chartarum, Lappodochium lageniforme, Dictyochaeta simplex, Stachybotrys nephrosfora e S. globosa, observando a formação de halo de inibição e agressividade dos fungos por meio de uma escala de nota. Foi avaliado também o crescimento do fitopatógeno na concentração $20 \%$ para selecionar filtrado de sapróbios com atividade antimicrobiana. Posteriormente os filtrados dos sapróbios selecionados foram estudados nas concentrações 5; 10; 15 e $20 \%$, avaliando o crescimento micelial de A. solani. Os sapróbios $L$. lageniforme e G. macrocladum, apresentaram maior crescimento micelial em relação a $A$. solani sete dias após a repicagem do fitopatógeno. Aos 15 dias somente o $L$. lageniforme conteve o patógeno. No teste de confrontação direta os fungos $L$. lageniforme e G. macrocladum ocuparam uma maior área na placa de Petri que o patógeno. Os filtrados dos fungos G. macrocladum, C. inaequalis, P. terrestris, S. globosa e C. eragrostidis na concentração de $20 \%$ promoveram redução no crescimento micelial de $A$. solani de 34, 21, 19, 10 e 10\%, respectivamente. Ao analisar o efeito das concentrações dos filtrados no crescimento micelial de A. solani, observou dose-dependência em todos os tratamentos, com máxima inibição do crescimento para os filtrados de G. macrocladum, C. inaequalis, $P$. terrestris, S. globosa e C. eragrostidis, respectivamente, na concentração $20 \%$.

Palavras-chave: controle biológico, ação antimicromiana, fitopatógeno.

\section{ABSTRACT}

Solino, A.J.S.; Oliveira, J.B.S.; Schwan-Estrada, K.R.F.; Marianna Santos Rodrigues Alencar, Ribeiro, L.M. Antagonistic potential and in vitro control of Alternaria solani by saprobic fungi. Summa Phytopathologica, v.43, n.3, p.199-204, 2017.

Alternaria solani, the etiological agent of early blight, is considered a phytopathogen of great economic impact on tomato crop, causing great losses to farmers. The aim of this study was to assess the antagonistic potential for direct confrontation, the production of volatile compounds and the in vitro antimicrobial activity of saprobic fungal filtrate against $A$. solani. Thus, the phytopathogen $A$. solani was confronted with the saprobic fungi Volutella minima, Memnoniella echinata, M. levispora, Curvularia eragrostidis, C. inaequalis, Gonytrichum chlamydosporium, G. macrocladum, Pseudobotrytis terrestris, Pithomyces chartarum, Lappodochium lageniforme, Dictyochaeta simplex, Stachybotrys nephrosfora and S. globosa, to observe inhibition zone formation and aggressiveness of the fungi according to a score scale. The phytopathogen growth was also evaluated at the concentration of $20 \%$ to select the saprobe filtrate with antimicrobial activity. Subsequently, the

Keywords: biological control, antimicrobial activity, plant pathogen. selected saprobe filtrates were studied at the concentrations of $5 ; 10 ; 15$ and $20 \%$, evaluating the mycelial growth of $A$. solani. The saprobes L. lageniforme and G. macrocladum showed greater mycelial growth, compared to A. solani, at seven days after transferring the phytopathogen. At 15 days, only L. lageniforme contained the pathogen. In the direct confrontation test, the fungi $L$. lageniforme and G. macrocladum occupied a larger area on the Petri dish, in contrast to the pathogen. The fungal filtrates G. macrocladum, C. inaequalis, P. terretris, $S$. globosa and C. eragrostidis, at a concentration of $20 \%$, promoted a reduction in the mycelial growth of $A$. solani by $34,21,19,10$ and $10 \%$, respectively. Analyzing the effect of the filtrate concentrations on the mycelial growth of $A$. solani, dose-dependence was observed in all treatments, with maximum growth inhibition for filtrates of G. macrocladum, C. inaequalis, P. terretris, S. globosa and C. eragrostidis, respectively, at the concentration of $20 \%$.
Os cultivos agrícolas estão sujeitos a diversas doenças causadas por uma ampla gama de fitopatógenos (12). As alternarioses são doenças fúngicas causadas pelas espécies do gênero Alternaria que estão amplamente distribuídas no mundo, infectando principalmente hortaliças (22). A pinta preta, causada por Alternaria solani, é considerada uma doença de grande importância econômica nas culturas de tomate e batata, com relatos de 6 a 100\% de danos na produção, caso não sejam adotadas medidas de controle preventivas e curativas (23).

Produtos com atividade antimicrobiana direta, como os fungicidas químicos é um método bastante difundido e procurado no setor agrícola para o controle de doenças, pois apresentam resultados rápidos (1). Outro importante e crescente método de controle de fitopatógenos é o biocontrole, que utiliza microrganismos como bactérias, actinomicetos e fungos. Este método de controle de doenças de plantas pode ser obtido por meio de diferentes tipos de interação entre os microrganismos, como o parasitismo, antibiose, competição, entre outros (17).

Fungos e rizobactérias com propriedades antagônicas constitui uma estratégia de grande interesse e importância para o controle biológico, 
utilizados como bioprotetores que apresentam ação fungicida e inseticida (5). Atualmente, poucos são os produtos disponíveis no mercado que atendem as necessidades dos produtores e a maioria não é devidamente registrada para o uso em escala comercial (5). Segundo Köhl et al. (12), o desenvolvimento de novos produtos para o controle biológico de doenças de plantas requer triagem de um número elevado de candidatos antagonistas, precisando cumprir distintas exigências além do controle do fitopatógeno, tais como, serem seguros, de baixo custo e apresentar amplo mercado consumidor.

Os fungos representam uma importante fonte de novas moléculas químicas, estima-se que no mundo há 1.5 milhões de espécies de fungos e que somente $1 \%$ tem sido pesquisado quanto ao espectro de produção de metabólitos secundários (24). Recentemente, pesquisas têm se concentrado no estudo de metabólitos secundários produzidos por estes, com propósito de isolar substâncias biotivas para o desenvolvimento de novos produtos para o controle de doenças de plantas. Cita-se, por exemplo, as estrobilurinas que pertencem ao grupo de compostos químicos produzidos pelo fungo Strobilurus tenacellus e representa o desenvolvimento mais bem sucedido de fungicidas baseados em compostos derivados de fungos (16). Muitos trabalhos têm indicado a excelente ação dos fungos como produtores de metabólitos capazes de controlar fitopatógenos.

Os compostos secundários, voláteis, produzidos por fungos decompositores são também considerados de grande relevância no controle biológico de fitopatógenos, visto a sua capacidade em difundirse por todo ambiente e agir em locais distantes do sítio de ação (5).

Considerando a importância dos microrganismos e o pequeno número de espécies estudadas, espera-se que estes possam representar uma fonte promissora de produtos naturais a serem descobertos. Assim, o objetivo deste trabalho foi verificar o potencial antagonista por confronto direto, produção de voláteis e atividade antimicrobiana in vitro de filtrado de fungos sapróbios contra Alternaria solani.

\section{MATERIAL E MÉTODOS}

Os experimentos foram realizados no Laboratório de Controle Alternativo e Indução de Resistência da Universidade Estadual de Maringá, no período de Janeiro 2012 a Dezembro de 2013, em Maringá, PR.

O isolado de $A$. solani, utilizado nesta pesquisa, foi cedido pela Universidade Estadual do Oeste do Paraná, sendo plaqueado em meio de cultura BDA (batata, dextrose e ágar) e mantido em biochemical oxygen demand (B.O.D), a $25^{\circ} \pm 2{ }^{\circ} \mathrm{C}$. Os isolados dos fungos sapróbios Volutella minima, Memnoniella echinata, M. levispora, Curvularia eragrostidis, C. inaequalis, Gonytrichum chlamydosporium, G. macrocladum, Pseudobotrytis terrestris, Pithomyces chartarum, Lappodochium lageniforme, Dictyochaeta simplex, Stachybotrys nephrosfora e $S$. globosa foram fornecidos pela Universidade Estadual de Feira de Santana, cultivados em meio BDA e mantidos em B.O.D a $25^{\circ} \mathrm{C} \pm 2{ }^{\circ} \mathrm{C}$. Posteriormente, foram retirados dois discos de aproximadamente $7 \mathrm{~mm}$ contendo micélio e estes repicados para erlenmeyer com $200 \mathrm{~mL}$ de meio de cultura líquido (batata dextroseBD), previamente esterilizado, e incubados em B.O.D a $25^{\circ} \pm 2{ }^{\circ} \mathrm{C} \mathrm{com}$ fotoperíodo de 12 horas de luz durante 20 dias. Após este período, os meios líquidos contendo os fungos sapróbios foram filtrados em papel Whatman $n^{\circ} 1$ para separação do micélio. Uma segunda filtragem foi realizada em sistema Millipore com membrana de $0,45 \mu \mathrm{m}$ de diâmetro de poro, para esterilização dos filtrados obtidos.
Para avaliação do potencial antagônico e da influência dos filtrados produzidos pelos fungos sapróbios, foram realizados ensaios in vitro por meio do teste de confronto por pareamento direto e teste de produção de metabólitos voláteis e não voláteis dos fungos sapróbios para inibição do crescimento micelial de $A$. solani.

A atividade antagônica dos fungos sapróbios à $A$. solani foi realizado por meio de teste de confronto direto por pareamento das culturas, em placas de Petri, contendo BDA. Para isto, discos de cultura dos fungos sapróbios foram repicados, três dias antes da repicagem do fitopatógenos, sendo colocados a uma distância de aproximadamente $1,0 \mathrm{~cm}$ da borda, em posições opostas. As placas foram incubadas em B.O.D, com temperatura de $25^{\circ} \pm 2{ }^{\circ} \mathrm{C}$ e fotoperíodo de 12 horas luz.

$\mathrm{Na}$ avaliação mensurou-se o tamanho do halo de inibição $(\mathrm{cm})$ entre o micélio de $A$. solani e do sapróbio aos sete e quinze dias após o repique do fitopatógeno, atribuindo-se nota pela escala proposta por Bell et al. (4): 1- Antagonista cresce por toda placa; 2 - Antagonista cresce sobre 2/3 da placa; 3 - Antagonista e patógeno crescem até $1 / 2$ da placa; 4- patógeno cresce sobre $2 / 3$ da placa e 5 - patógeno cresce por toda a placa.

O ensaio foi conduzido em delineamento inteiramente casualizados (DIC), com quatro repetições e os dados obtidos foram submetidos a análise de variância a $5 \%$ de probalibilidade e posteriormente comparados pelo teste de Scott-Knott a $5 \%$ de probabilidade.

Para o teste de produção de metabólitos voláteis por fungos sapróbios com influência no crescimento micelial de $A$. solani foram utilizadas placas de Petri de poliestireno com divisão central, contendo meio de cultura BDA. Em uma das partes da placa foi repicado um disco de micélio (7 mm) do antagonista (fungos sapróbios) e na outra o disco de mesmo diâmetro do fitopatógeno, simultaneamente. A testemunha recebeu um disco de $A$. solani em apenas uma seção da placa de Petri. As placas foram vedadas com filme de PVC e em seguida incubadas em B.O.D a $25^{\circ} \pm 2{ }^{\circ} \mathrm{C}$ com fotoperíodo de 12 horas.

As avaliações do crescimento micelial do fitopatógneno foram realizadas após três dias do início do teste, medindo-se o raio $(\mathrm{cm})$ médio das colônias a partir da borda das placas. $\mathrm{O}$ experimento foi realizado em DIC com mesmo delineamento utilizado na atividade antagônica.

Para avaliar a atividade antimicrobiana dos filtrados de fungos sapróbios foram realizados dois experimentos in vitro. Primeiramente, foram selecionados fungos capazes de inibir ou retardar o crescimento de A. solani. Para isto, os filtrados foram diluídos a $20 \%$ em meio de cultura BDA fundente e vertidos em placas de Petri, onde foram repicados posteriormente discos do micélio $(7 \mathrm{~mm})$ do fitopatógeno. Como tratamento controle, utilizou-se o meio de cultura puro. Após a repicagem, as placas foram mantidas em B.O.D., a $25^{\circ} \pm 2{ }^{\circ} \mathrm{C}$ com fotoperíodo de 12 horas de luz e o crescimento micelial de $A$. solani foi mensurado quando o tratamento controle ocupou $2 / 3$ da placa, considerando o diâmetro $(\mathrm{cm})$ médio das colônias em dois sentidos perpendiculares. Este experimento foi realizado em DIC, com mesmo delineamento utilizado na atividade antagônica.

Os filtrados dos fungos sapróbios selecionados na primeira etapa, foram utilizados no segundo experimento para avaliar o efeito de diferentes concentrações dos filtrados sobre o crescimento micelial de A. solani. Neste experimento também foi utilizado DIC, em esquema de parcela subdividida $5 \times 5$, com quatro repetições. A parcela foi representada pelos filtrados de cinco espécies de fungos sapróbios $(C$. inaequalis, P. terrestris, S. globosa, C. eragrostidis e G. macrocladum) selecionados na primeira etapa, e para a subparcela, considerou-se as concentrações $(0 ; 5 ; 10 ; 15$ e $20 \%)$ dos filtrados dos fungos. Para este experimento, os filtrados foram incorporados ao meio de cultura 
BDA fundente, de maneira a se obter as diferentes concentrações, e após a solidificação dos meios, foi realizada a repicagem de um disco de micélio de $7 \mathrm{~mm}$ provenientes de colônia pura de $A$. solani, para os mesmos. As placas foram incubadas em B.O.D., a $25{ }^{\circ} \mathrm{C} \pm 2{ }^{\circ} \mathrm{C}$ com fotoperíodo 12 horas luz. Como tratamento controle, utilizouse o meio de cultura puro e a avaliação do crescimento micelial foi realizada quando o patógeno tomou $2 / 3$ das placas do tratamento controle, medindo-se o diâmetro $(\mathrm{cm})$ médio das colônias em dois sentidos perpendiculares entre si e tomando como valor de crescimento as médias das duas medidas. Os dados obtidos foram utilizados para a análise de regressão $(\mathrm{p}>0,5)$.

\section{RESULTADOS E DISCUSSÃO}

Os isolados de L. lageniforme e G. macrocladum, apresentaram maior crescimento micelial em relação a $A$. solani na avaliação realizada com sete dias após a repicagem do fitopatógeno, os quais receberam nota 2 . Entretanto, somente a primeira espécie conteve o patógeno em apenas 1/4 da placa na avaliação aos 15 dias, indicando um moderado desempenho na competição por espaço e nutriente. Os demais tratamentos apenas contiveram a expansão do patógeno de acordo com a escala (4) (Figura 1).

No pareamento de $A$. solani com os fungos sapróbios $L$. lageniforme e G. macrocladum, observa-se que ambos ocuparam $67 \%$ da placa na primeira avaliação. Amorim et al. (1) encontraram linhagens de Trichoderma altamente antagônicas a Sclerotium rolfsii com aproximadamente $80 \%$ de controle do crescimento micelial. Assim, o $L$. lageniforme e o G. macrocladum como potenciais antagonistas à A. solani.

No confronto dos fungos sapróbios com $A$. solani observou-se que os sapróbios S. globosa, S. nephrosfora, P. chartarum e G. macrocladum apresentaram halo de inibição aos sete dias após a repicagem do patógeno em placa de Petri, mantendo-se após quinze dias (Tabela 1). Entre eles destaca-se o G. macrocladum com halo de $2,95 \mathrm{~cm}$. Na segunda avaliação, aos quinze dias, notou-se uma redução na área do halo de inibição de todos os sapróbios em relação a primeira avaliação (Tabela 1).

A antibiose é definida como a interação na qual um ou mais metabólitos produzidos por um organismo têm efeito danoso sobre o
Tabela 1. Halo de inibição por fungos sapróbios confrontados com Alternaria solani após 7 e 15 dias de cultivo

\begin{tabular}{lcc}
\hline \multirow{2}{*}{ Fundos sapróbios } & \multicolumn{2}{c}{ Halo de inibição (cm) } \\
\cline { 2 - 3 } Controle (Alternaria solani) & Sete dias & Quinze dias \\
Lappodochium lageniforme & 0,00 & 0,00 \\
Stachybotrys nephrosfora & 0,00 & 0,00 \\
Gonytrichum macrocladum & 1,37 & 1,20 \\
Memnoniella levispora & 2,95 & 2,42 \\
Curvularia inaequalis & 0,00 & 0,00 \\
Pseudobotrytis terrestris & 0,00 & 0,00 \\
Stachybotrys globosa & 0,00 & 0,00 \\
Curvularia eragrostidis & 0,67 & 0,55 \\
Dictyochaeta simplex & 0,00 & 0,00 \\
Gonytrichum chlamydosporium & 0,00 & 0,00 \\
Pithomyces chartarum & 0,00 & 0,00 \\
Volutella minima & 0,67 & 0,40 \\
Memnoniella echinata & 0,00 & 0,00 \\
\hline
\end{tabular}

outro (19). Dentre as substâncias que podem ser sintetizadas, estão os metabólitos secundários tóxicos, como antibióticos e enzimas líticas capazes de inibir e destruir propágulos de fungos fitopatogênicos, semelhante aos resultados encontrados no teste de pareamento $S$. globosa, S. nephrosfora, P. chartarum e G. macrocladum se destacaram no experimento de confronto com o fitopatógeno A. solani. Remuska \& Dalla Pria (18) também observaram que a liberação de metabólitos (nãovoláteis) pelos isolados de Trichoderma spp., promoveram antagonismo Sclerotinia sclerotiorum isolado de tomateiro, alface e fumo, como inibição de $94 \%$ ao testar o isolado TSM1, 93\% para o J10 e 86\% para I1. Cerca de 40 substâncias produzidas por Trichoderma spp. possuem atividade antibiótica, não incluindo as enzimas (13).

O fungo sapróbio G. macrocladium demonstrou que possui habilidades como agente de biocontrole por meio de competição por espaço e por antibiose. Segundo Bettiol \& Morandi (5), a utilização

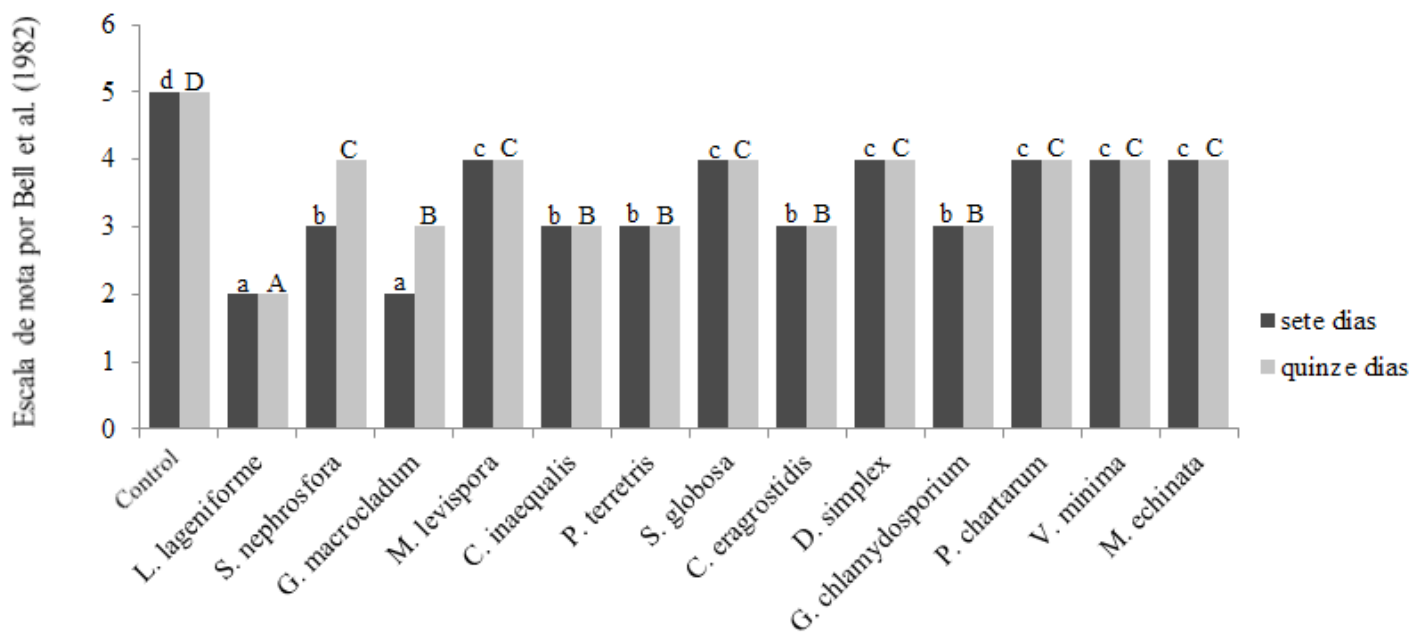

Espécies de fungos sapróbios

Figura 1. Médias das notas do teste de confronto direto, por pareamento, entre fungos sapróbios e Alternaria solani utilizando a escala de Bell et al. (4): 1- Antagonista cresce por toda placa; 2 - Antagonista cresce sobre 2/3 da placa; 3 - Antagonista e patógeno crescem até 1/2 da placa; 4- patógeno cresce sobre $2 / 3$ da placa e 5 - patógeno cresce por toda a placa.

* Médias seguidas de mesma letra minúscula nas colunas cinza escura e maiúscula nas colunas cinza claro não diferem entre si pelo teste de Scott-Knott (p<0,05). 
de mais de um mecanismo de controle por agentes antagonistas é uma característica recomendável, combinando-se antibiose, parasitismo e/ou competição. Trichoderma, o principal fungo pesquisado em programas de biocontrole, utiliza a competição por nutrientes e espaço, além de produzir metabólitos que impedem a germinação de esporos ou o crescimento e esporulação de fitopatógenos.

Ao avaliar a influência da produção de metabólitos voláteis dos fungos sapróbios no crescimento micelial de $A$. solani não foi observado diferença estatística entre os tratamentos (Tabela 2), de forma que a maior inibição do patógeno $(1,6 \%)$ foi verificada na presença dos fungos C. inaequalis, $S$. globosa e $S$. nephrosfora.

Botrel (7) estudando o efeito de interações entre sapróbios e fitopatógenos observou inibição de Pseudomonas seringae pv. garcae quando na presença do sapróbio Pithomyces macrosporus, resultados não observados ao se estudar a interação in vitro dos sapróbios testados sobre $A$. solani. Interações positivas, negativas e neutras podem ocorrer ao se avaliar o efeito da produção de metabólitos voláteis produzidos por microrganismos, como as bactérias e fungos, além de considerar também relações específicas entre eles (14). Humphris et al. (9) estudando os efeitos de metabólitos secundários voláteis produzidos por Trichoderma pseudokoningii, T. viride e T. aureoviride sobre a taxa de crescimento de dois isolados de Serpula lacrymans, observaram que esta foi afetada dependendo da interação microbiana e indicaram envolvimento de especificidade nos testes. As atividades dos compostos voláteis produzidos por microrganismos decompositores também podem apresentar efeito bastante variado em diferentes espécies de fungos, inibindo ou estimulando o crescimento micelial de outros fungos (15). Microrganismos que produzam metabólitos voláteis podem ser utilizados em conjunto com outros métodos de controle (20).

Talibi et al. (21), descreveram entre os métodos de controle de fitopatógenos de pós-colheita de frutas o uso de compostos voláteis como importante e promissor recurso. Arrebola et al. (2), pesquisando o efeito antifúngico de compostos voláteis produzidos por estirpes de Bacillus subtilis e B. amyloliquefaciens contra isolados de Penicillium digitatum, Penicillium italicum e Penicillium crustosum indicaram a

Tabela 2. Avaliação da produção de compostos voláteis de fungos sapróbios com potencial de inibição no crescimento micelial de Alternaria solani

\begin{tabular}{lc}
\hline Tratamentos & Diâmetro de crescimento (cm) \\
Lappodochium lageniforme & $3,02 \mathrm{a}$ \\
Stachybotrys nephrosfora & $2,97 \mathrm{a}$ \\
Gonytrichum macrocladum & $3,00 \mathrm{a}$ \\
Memnoniella levispora & $3,05 \mathrm{a}$ \\
Curvularia inaequalis & $2,97 \mathrm{a}$ \\
Pseudobotrytis terrestris & $3,05 \mathrm{a}$ \\
Stachybotrys globosa & $2,97 \mathrm{a}$ \\
Curvularia eragrostidis & $3,05 \mathrm{a}$ \\
Dictyochaeta simplex & $3,02 \mathrm{a}$ \\
Gonytrichum chlamydosporium & $3,05 \mathrm{a}$ \\
Pithomyces chartarum & $3,07 \mathrm{a}$ \\
Volutella mi nima & $3,07 \mathrm{a}$ \\
Controle & $3,02 \mathrm{a}$ \\
\hline CV\% & 2,31 \\
\hline
\end{tabular}

Médias seguidas de mesma letra não diferem entre si pelo teste de Scott-Knott $(\mathrm{p}<0,05)$. eficiência de $B$. amyloliquefaciens para o controle de $P$. crustosum em sistemas de pós-colheita de citrus na África do sul.

Na Tabela 3 pode-se observar que os filtrados dos fungos sapróbios G. macrocladum, C. inaequalis, P. terrestris, S. globosa e C. eragrostidis na concentração de $20 \%$ apresentaram efeito fungistático sobre o crescimento micelial de $A$. solani, reduzindo-o em 34, 21, 19, 10 e 10\%, respectivamente, quando comparados ao tratamento controle.

A ação fungistática promovida por G. macrocladum, C. inaequalis, P. terrestris, $S$. globosa e C. eragrostidis sobre A. solani indica que a produção de metabólitos não voláteis destes microrganismos é capaz de controlar fitopatógenos. Os fungos $G$. macrocladium e $S$. globosa apresentaram halo de inibição no teste de pareamento de culturas com A. solani e concluído sua atividade contra o patógeno no teste de metabólitos não voláteis. Para Bonfim et al. (6), os antimicrobianos são produtos do metabolismo secundário de seus produtores, que atuam promovendo a redução ou paralisação do crescimento e ou esporulação de fitopatógenos.

Segundo Remuska \& Dalla Pria (18) a maioria dos microrganismos produzem um ou mais compostos com atividade inibitória para outro, e em alguns casos, os antimicrobianos sintetizados têm demonstrado ser particularmente eficazes na supressão de patógenos de plantas e das doenças causadas por estes. Figueiredo \& Silva (8), observaram que extrato de basidiocarpo de Lentinus crinitus e Pycnoporus sanguineus promoveram redução no crescimento micelial de Fusarium spp. em 50 e $60 \%$ em experimentos in vitro, indicando potencial para desenvolvimento de tecnologia que utilize extratos a base de fungos sapróbios como alternativa para o combate de fitopatógenos. Atividade antimicrobiana de extrato aquoso e filtrados de fungos sapróbios também são apresentadas em outras pesquisas como a de Baldo (3).

Ao analisar a influência das concentrações dos filtrados dos fungos G. macrocladum, C. inaequalis, P. terrestris, S. globosa e $C$. eragrostidis no crescimento micelial de $A$. solani, observou-se no modelo de regressão linear com efeito dose-dependente para todos os filtrados. Portanto, os tratamentos promoveram inibição do crescimento de 22, 34, 61 e 8\%, respectivamente, com a aplicação da concentração

Tabela 3. Efeito de filtrados de fungos sapróbios sobre o crescimento micelial de Alternaria solani em meio BDA

\begin{tabular}{lc}
\hline Tratamentos & Diâmetro da colônia (cm) \\
Controle & $6,32 \mathrm{a}$ \\
Lappodochium lageniforme & $6,32 \mathrm{a}$ \\
Stachybotrys nephrosfora & $6,32 \mathrm{a}$ \\
Gonytrichum macrocladum & $5,65 \mathrm{~b}$ \\
Memnoniella levispora & $6,17 \mathrm{a}$ \\
Curvularia inaequalis & $4,95 \mathrm{c}$ \\
Pseudobotrytis terrestris & $5,62 \mathrm{~b}$ \\
Stachybotrys globosa & $5,10 \mathrm{c}$ \\
Curvularia eragrostidis & $4,17 \mathrm{~d}$ \\
Dictyochaeta simplex & $6,25 \mathrm{a}$ \\
Gonytrichum chlamydosporium & $6,45 \mathrm{a}$ \\
Pithomyces chartarum & $6,35 \mathrm{a}$ \\
Volutella minima & $6,20 \mathrm{a}$ \\
Memnoniella echinata & $6,15 \mathrm{a}$ \\
\hline CV\% & 6,31 \\
\hline
\end{tabular}

Médias seguidas de mesma letra não diferem entre si pelo teste de Scott-Knott $(\mathrm{p}<0,05)$. 


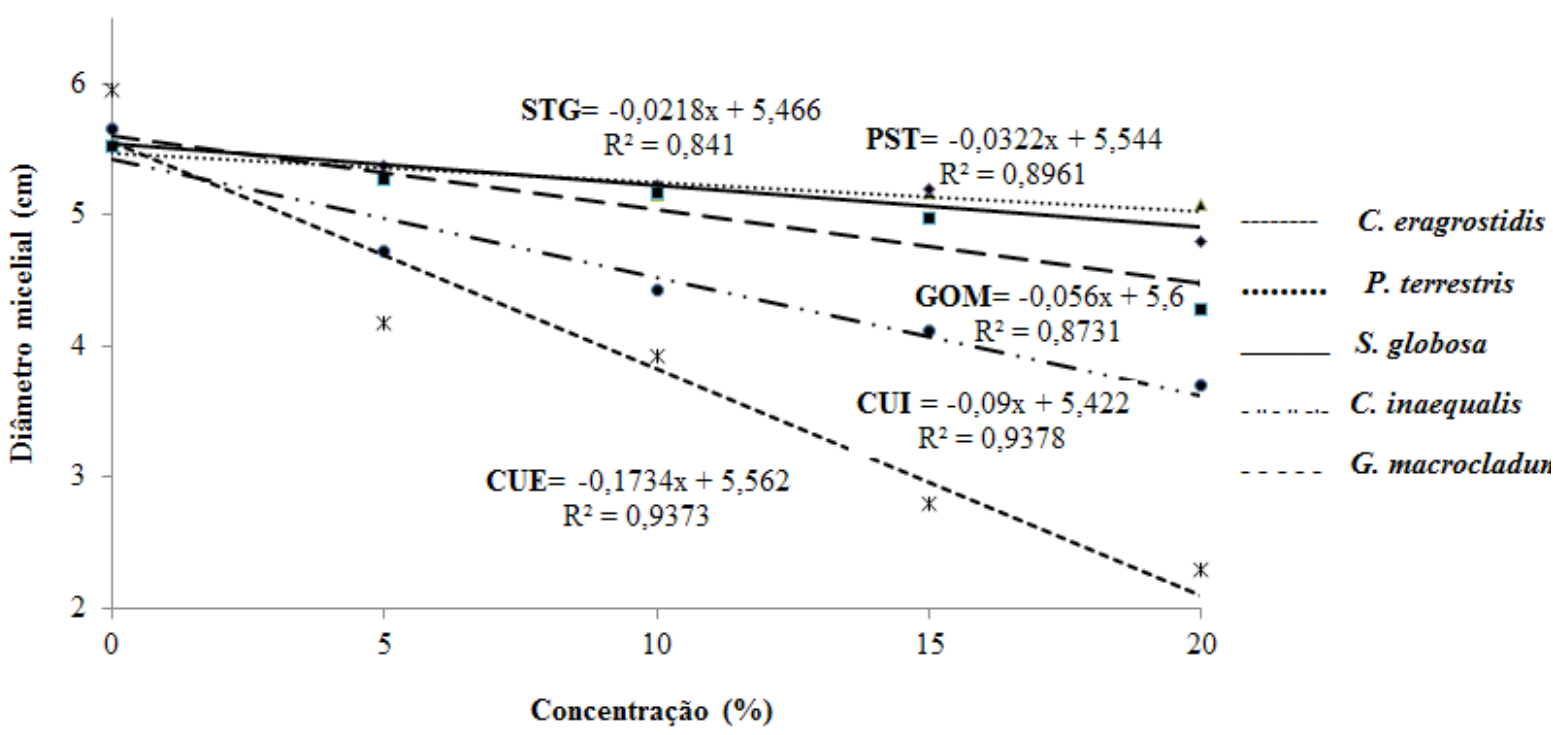

Figura 3. Efeito de concentrações de filtrados de fungos G. macrocladum, C. inaequalis, P. terrestris, S. globosa e C. eragrostidis sobre o crescimento micelial de Alternaria solani em meio BDA.

20\%, quando comparado a concentração zero (Figura 3).

Pal \& Gardener (17) inferiram que para uma substância antimicrobiana ser capaz de controlar um microrganismo in vitro ou in situ, é necessária a produção desta substância em quantidades suficientemente tóxica ao patógeno e assim resultar em um efeito de biocontrole. Isto pode esclarecer os resultados obtidos no estudo da influência dos filtrados de fungos sapróbios sobre $A$. solani testado in vitro, observando-se menor crescimento da colônia conforme aumentou a concentração e consequentemente o agente antimicrobiano presente neste.

Luo et al. (10), procurando novos fungicidas de origem natural, verificaram que o fungo Albatrellus dispansus produz substâncias com ação in vitro a Fusarium graminearum e S. sclerotiorum com controle de 80 e $86 \%$, respectivamente. Resultados superiores aos observados pelo sapróbios G. macrocladum, C. inaequalis, P. terrestris, S. globosa e C. eragrostidis.

Luo et al. (11) observaram que sesquiterpenos isolados dos corpos de frutificação de Lactarius rufus reduziu em $68 \%$ do crescimento micelial in vitro de Alternaria brassicae e apresentou menor eficiência contra o fungo Alternaria alternata, reduzindo o crescimento em $38 \%$. Estes resultados podem estar relacionados a especificidade da ação das moléculas antifúngicas, podem ainda indicar a utilização de outros fitopatógenos em testes antimicrobianos de filtrados produzidos por fungos sapróbios.

Os resultados apresentados permitiram verificar que o fungo sapróbio Lapodoquium lageniforme apresentou competitividade moderada quando confrontado diretamente com A. solani.

Os fungos sapróbios não produziram metabólitos voláteis capazes de influenciar o crescimento micelial de $A$. solani.

Os filtrados de fungos sapróbios Curvularia inaequalis e $C$. eragrostidis apresentaram capacidade de reduzir o crescimento micelial do fitopatógeno $A$. solani in vitro na concentração de $20 \%$.

\section{AGRADECIMENTOS}

Agradecemos ao Programa de pós-graduação em agronomia da Universidade Estadual de Maringá (UEM), a CAPES, ao CNPQ, a
FAPESP e Fundação Araucária.

\section{REFERÊNCIAS}

1. Amorim, L.; Bergamin FilhO, A.; Camargo, L.E.A.; Rezende, J.A. M. 68 (Ed.). Manual de fitopatologia: doencas das plantas cultivadas. São Paulo: Editora Agronomica Ceres, 2011, v. 1, 704 p.

2. Arrebola, E.; Sivakumar, D.; Korsten, L. Effect of volatile compounds produced by Bacillus strains on postharvest decay in citrus. Biological Control, Lexington, v. 53, 122-128, 2010.

3. Baldo, M. Aspctos histológicos e bioquímicos da indução de resistência em feijoeiro e atividade antifúngica por derivados de Pycnoporus sanguineus. 2008. 72 f. Dissertação (Mestrado em Agronomia) - Universidade Estudal do Oeste do Paraná, Marechal Cândido Rondon.

4. Bell, D. K; Wells, H. D.; Markham, C. R. In vitro antagonismo of Trichoderma species against Six fungal plant pathogens. Ecology and Epidemiology, Geogia, v. 72, n. 4, p. 379-382, 1982.

5. Bettiol, W.; Morandi, M. A. B. Controle biológico de doenças de plantas: uso e perspectivas. Brasilia: Embrapa Meio Ambiente, 2009.

6. Bomfim, M. P.; São José, A. R.; Rebouças, T. N. H.; Almeida, S. S. de; Souza, I. V. B.; Dias, N. O. Avaliação antagônica in vitro e in vivo de Trichoderma spp. a Rhizopus stolonifer em maracujazeiro amarelo. Summa phytopathologica, Jaguariúna, v. 36, n. 1, p. 61-67, 2010.

7. Botrel, D. A. Fungos sapróbios como agentes de biocontrole da Mancha Aureolada (Psedomonas syringae pv. Garcae) no cafeeiro. 2013, 57p. Dissertação (mestrado em fitopatologia) - Universidade Federal de Lavras, Lavras.

8. Figueiredo, A.; Silva, A. C. e. Atividade "in vitro" de extratos de Pycnoporus sanguineus e Lentinus crinitus sobre o fitopatógeno Fusarium sp. Acta Amazonica, Manaus, v. 44, n. 1, p. 1-8, 2014.

9. Humphris, S. N.; Bruce, A.; Buultjens, E.; Wheatley, R. E.; The effects of volatile microbial secondary metabolites on protein syntesis in Serpula lacrymons. FEMS Microbiology Letters, Oxford, v. 210, p. 215-219, 2002.

10. Luo, D. Q.; Shao, H. J.; Zhu, H. J.; Liu, J. K. Activity in vitro and in vivo against plant phatogenic fungi of grifolin isoleted from the basiociomycetes Albatrellus dispansus. Zeitschrift für Naturforschung, St Andrews, v. 60, p. 50-56, 2004

11. Luo, D. Q.; Wang, F.; Bian, X. Y.; Liu, J. K. Rufuslactone a new antifungal sesquiterpene from the fruiting bodies of the basiociomycetes Lactarius rufus. Journal Antibiotics, Tokyo, v. 58, n. 7, p. 456-459, 2005.

12. Köhl, J.; Postma, J.; Nicot, P.; Ruocco, M.; Blum. B. Stepwise screening of microorganisms for commercial use in biological control of plant-pathoge- 
nic fungi and bacterial. Biological Control, Lexington, v. 57, p. 1-12, 2011.

13. Machado, D. F. M.; Parzianello, F. R.; Silva, A. C. F. da; Antoniolli, Z. I. Trichoderma no Brasil: o fungo e o bioagente. Revista de Ciências Agrárias, Recife, v.35, n. 1, 2012.

14. Mackie, A.; Wheatley, R.E. Efects and incidence of volatile organic compound interactions between soil bacterial and fungal isolates. Soil Biology \& Biochemistry, Leicestershire, v. 31, p. 375-385, 1999.

15. Mangenot, F.; Diem, H. G. Fundamentals of biological control. In: Krupa, S. V.; Dommergues, Y. R. (eds). Ecology of root pathogens, Amstenolam: Elsevier, 1979.

16. Parreira, D. F.; Neves, W. dos S.; Zambolim, L. Resistência de Fungos a Fungicidas Inibidores de Quinona. Revista Trópica, Chapadinha, v. 3, n.2, p. 25, 2009.

17. Pal, K. K.; Gardener, M. C. S. Biological Control of Plant Pathogens. The Plant Health Instructor, Ithaca, v. 1, p. 1-15, 2006.

18. Remuska, A. C.; Dalla Pria, M. Efeito de Bacillus thuringiensis e Trichoderma sp. No crescimento de fungos fitopatogênicos. Ciências Exatas e da Terra, Ciências Agrárias e Engenharias, Ponta Grossa, v. 13, n. 3, p. 31-36, 2007.
19. Stadnik, M. J.; Bettiol, W. Controle biológico de oídios. In: Melo, I. S. de; Azevedo, J. L. de (Ed.). Controle biológico. Jaguariúna: Embrapa Meio Ambiente, 2000, v. 3, cap. 4, p. 95-116.

20. Strobel, G. A.; Spang, S.; Kluck, K.; Hess, W. M.; Sears, J.; Livinghouse, T. Synergism among volatile organic compounds resulting in increased antibiosis in Oidium sp. FFMS Microbiological Letters, Oxford, v. 283, p. $140-145,2008$.

21. Talibi, I.; Boubaker, H.; Boudyach, E. H.; Aoumar, A. B. Alternative methods for hte controlo f postharvest citrus diseases. Journal Applied Microbiology. Bedford, v. 1, p. 1-16, 2014.

22. Töfoli, J. G.; Domingues, R. J. Alternarioses em hortaliças: sintomas, etiologia e manejo intregado. Biológico, São Paulo, v. 66, n. 1/2, p. 23-33, 2004.

23. Töfoli, J. G.; Melo, P. C. T.; Domingues, R. J.; Ferrari, J. T. Requeima e pinta preta na cultura da batata: importância, características e manejo sustentável. Biológico, São Paulo, v. 75, n. 1, p. 33-40, 2013.

24. Weber, R. W. S.; Kappe, R.; Paululat, T.; Mosker, E.; Anke, H.; Anti-Candida metabolites from endo-phytic fungi; Phytochemistry, Washington, v. 68 : 886-892, 2007. 